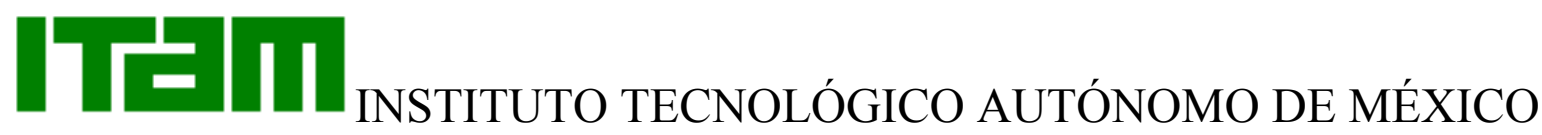

\section{CENTRO DE INVESTIGACIÓN ECONÓMICA}

\section{Discussion Paper Series}

\section{When Are Stabilizations Delayed?}

Alesina-Drazen Revisited

César Martinelli

Instituto Tecnológico Autónomo de México

and

Raúl Escorza

Instituto Tecnológico Autónomo de México

June 2004

Discussion Paper 04-08

Av. Camino a Santa Teresa \# 930

Col. Héroes de Padierna

México, D.F. 10700

$\mathrm{M}$ E X I C O 


\title{
When Are Stabilizations Delayed? Alesina-Drazen Revisited
}

\author{
César Martinelli and Raúl Escorza* \\ ITAM
}

June 2004

\begin{abstract}
In an influential article, Alesina and Drazen (1991) model delay of stabilization as the result of a struggle between political groups supporting reform plans with different distributional implications. In this paper we show that ex ante asymmetries in the costs of delay for the groups will reduce the probability of conflict and will lead to a shorter expected delay. Accurate common information about the cost of delay may lead to no delay at all. In an asymmetric conflict, a wider divergence in the distributional implications of reform will reduce the probability of conflict but will lead to a longer expected delay.
\end{abstract}

Keywords: Stabilization delay, economic reforms, war of attrition JEL D72, E60

*Address correspondence to César Martinelli, Centro de Investigación Económica, Instituto Tecnológico Autónomo de México, Camino Santa Teresa 930, 10700 México DF (martinel@itam.mx). 


\section{Introduction}

In their (1991) article titled "Why are stabilizations delayed?", Alesina and Drazen provide a model where delay of economic reforms is the result of a distributional conflict between political groups uncertain about the capacity of their rivals to bear the cost of inflation and other distortions caused by delay. Although all political groups understand the need for reform, and although all suffer while reforms are delayed, each has an incentive to resist the adoption of reform in the hope that the others will capitulate first and agree to bear a disproportionate burden of the reform program. The model predicts that reform delay will be shorter the more similar are the distributional consequences of different reform plans, and the higher is the cost of delay for all groups. As shown by Drazen and Grilli (1993), this last result supports the common view that financial crises and other pains resulting from budgetary instability have the virtue of inducing earlier expected reform. Alesina and Drazen's (1991) analysis has been extended elsewhere by Alesina and Perotti (1995), Casella and Eichengreen (1996), Guidotti and Vegh (1999), Spolaore (2003), among others, and has achieved textbook status in the presentations by Persson and Tabellini (2000: 361-364) and Drazen (2000: 432-439). ${ }^{1}$

A key simplification in Alesina and Drazen's (1991) seminal contribution and the subsequent literature is the assumption that the political groups in conflict are identical ex ante, in the sense that the (privately known) cost of inflation for each group is independently drawn from the same distribution. Ex ante symmetry, however, is a very strong assumption. In general, the constituencies of rival political groups are not expected to be similarly affected by pre-stabilization distortions. For instance, inflation is commonly believed to be a regressive tax. ${ }^{2}$ Thus, political groups representing on average lower income constituencies are likely to be the more affected by delaying the stabilization. Moreover, a symmetric setup precludes the consideration of (publicly observed) changes in the cost of inflation for one of the groups

\footnotetext{
${ }^{1}$ While Alesina and Drazen were the first authors to use the war of attrition model in a macroeconomic context, they build on the biological model of Maynard Smith (1974) and Riley (1980), and the public-good model of Bliss and Nalebuff (1984).

${ }^{2}$ Erosa and Ventura (2000) argue this point in a monetary economy with heterogenous household wealth composition and transaction patterns. Also, Romer and Romer (1999) find a negative correlation between the income of the poor and average inflation.
} 
in conflict. An example is the more extensive use of foreign currency by the richer segments of the population, reducing their cost of inflation. ${ }^{3}$

In this paper, we consider a model of stabilization delay due to conflicting (and possibly asymmetric) political groups. We show that a political group more exposed to inflation costs will be likely to cave in immediately, leading to immediate reform. If the expected cost of inflation increases for the more exposed group, the probability of immediate reform increases and the expected delay of stabilization is reduced. If the expected cost of inflation increases for the less exposed group, the effects are exactly the reverse. Thus, in contrast to the predictions from Alesina and Drazen (1991), the effect of a reduction in the cost of inflation, benefitting mostly the less exposed group, may be a shorter delay. In agreement with the predictions from Alesina and Drazen (1991), if the distributive consequences of reform become more unequal, a longer expected delay follows. There is a surprising twist, though: the probability of immediate agreement also increases. Intuitively, if the more exposed group is nearly indifferent between conceding immediately or entering the conflict, it will be convinced to concede immediately by the expectation of a longer conflict.

In terms of expected utility, we show that increasing the expected cost of inflation for the more exposed group will increase the (utilitarian) welfare of society, while increasing the expected cost for the least exposed group will reduce it. An increased divergence in the distributional implications of economic reform will reduce the expected utility of both groups. In synthesis, asymmetries in the losses due to stabilization delay will reduce the probability of conflict and increase (utilitarian) social welfare, while asymmetries in the distributional implications of reform will reduce the probability of conflict but decrease (unequivocally) social welfare.

Examples for our model can be drawn from the Latin American experiences with economic reform in the second half of the 1980s and first half of the 1990s. In that interval, Bolivia, Mexico, Peru, Argentina and Brazil adopted reform programs that combined balancing the fiscal accounts with large-scale privatization and overhauling of trade and industrial policies. As

\footnotetext{
${ }^{3}$ Financial adaptation to inflation is discussed by Labán and Sturzenegger (1994), who build on another influential contribution to the political economy of reform (Fernandez and Rodrik 1991). See also Sturzenegger (1997).
} 
Rodrik (1996) notes, this peculiar mix of policies was not unavoidable - in fact, some of the policies adopted may have complicated the stabilization effort. If we think of reform delay as the result of a distributive conflict, we have to conclude that in all those cases the groups favored by rightwing policies emerged as winners of the conflict, and their favorite blueprint for reform was implemented. Strikingly, the reforms were implemented by formerly populist presidents, often belonging to parties that had shown a penchant for interventionism in the past. In our view, this accentuates the character of concession of the reforms. ${ }^{4}$ Rather than by worsening conditions for everyone, reforms in Latin America may have been prompted by relative improvements in the ability to live with inflation and other distortions by the groups that eventually held the upper hand. At least from a utilitarian perspective, the lesson from our model is that financial adaptation by some groups in society may not have been bad for reform, contrary to what has been claimed in previous literature. Social polarization, in the sense of strong distributional consequences of different reform packages, may have been bad for reform though, as previously claimed by Alesina and Drazen (1991) and other authors. Looking at the future, our model predicts that the inconsistent policies characterizing stabilization delay are more likely to recur in countries with moderate to high - rather than extremely high - social polarization.

Formally, our model is an asymmetric war of attrition in the spirit of Nalebuff and Riley (1985) and Fudenberg and Tirole (1986). ${ }^{5}$ We select an equilibrium to the model following a suggestion of Nalebuff and Riley. We show that, in all equilibria but the most favorable one, a political group would benefit from committing with some arbitrarily small probability to never give up. A commitment strategy would consist, for instance, of selecting an ideologically-motivated leadership for the group. We focus on the "commitment-proof" equilibrium obtained by allowing each group to be com-

\footnotetext{
${ }^{4}$ Cukierman and Tommasi (1998) propose a different, but not incompatible, explanation of the apparent paradox of populist politicians implementing right-wing reforms in terms of their credibility.

${ }^{5}$ More recent contributions such as those of Krishna and Morgan (1997) or Bulow and Klemperer (1999) have extended the incomplete information war of attrition model to affiliated costs or multiple combatants and prizes, but have stuck to the analysis of the symmetric case.
} 
mitted with a (vanishingly small) probability. In order to perform comparative static exercises, we adopt a flexible functional form for the distribution of costs of the conflicting parties, and complement the analytical work with computer simulations. Finally, we show that if common information about the expected costs of inflation is accurate enough so that prior beliefs about the costs have different supports, then a nonnegligible probability of delay will be supported only by a positive probability of commitment or by large distributional consequences of reform.

Perraudin and Sibert (2000) and Hsieh (2000) have proposed other bargaining models of reform that allow for a positive probability of immediate agreement. They differ from our approach in that they consider a finitehorizon, one-sided incomplete information game with discrete time, with the uninformed party holding the ability to make reform proposals. Hsieh (2000) shows that increasing the costs of inflation proportionally for both parties leads to an increased probability of immediate agreement. Perraudin and Sibert (2000) show that increasing the cost of inflation only for the informed party may increase or decrease the probability of immediate agreement. This result is related in their case to the increased bargaining power of the uninformed party, for whom delay becomes a more attractive screening device. Neither of these two papers is concerned with the effects on stabilization delay of asymmetries in the expected costs of inflation to parties representing different segments of the domestic population. On another related contribution, Seddon Wallack (2003) has found evidence that countries with less accurate commonly accessible information tend to delay stabilization longer. While she attributes this result to disagreements about the expected costs and benefits of reform, we can note that in our setup better common information is likely to lead to a shorter delay. If the support of the distribution of costs for the two parties are different, which is likely to occur with accurate common information, the probability of delay may be near zero.

The remainder of the paper is organized as follows. The model is described in Section 2. Equilibrium selection is discussed in Section 3. Comparative statics results are presented in Section 4. Accurate information with respect to asymmetries in costs is investigated in Section 5. Section 6 concludes with remarks on the role of institutions and information in delayed stabilizations. 


\section{The model}

We consider a stripped-down version of the Alesina-Drazen model. At $t=0$ an economy is hit by a shock reducing tax revenues. From then until the date of stabilization, the government deficit $\tau$ has to be covered by distortionary taxes (a proxy for inflation ${ }^{6}$ ). There are two political groups or parties $(i=1,2)$. Before stabilization, (the representative consumer of) each party pays half of the distortionary taxes and in addition suffers some welfare loss $\theta_{i}$ that is private information to the party. For stabilization to occur, one of the two groups (which becomes the loser) has to agree to bear a fraction $\alpha>1 / 2$ of the new, nondistortionary taxation while the remainder is borne by the other group (the winner). Note that $\alpha$ measures the divergence between the distributional implications of the reform plans favored by the two groups, or "degree of polarization" of society. Welfare losses disappear with stabilization.

Ignoring gross income, which plays no role in the model, the flow utility for group $i$ before stabilization is: $U_{i}^{D}=-\tau / 2-\theta_{i}$. After stabilization, flow utility for the loser or conceding party becomes: $U_{i}^{L}=-\alpha \tau$. Flow utility for the winner becomes: $U_{i}^{W}=-(1-\alpha) \tau$. Groups are infinitely lived and discount the future according to $r$. The problem of each party is to maximize its expected lifetime utility by choosing a time to concede if the other party has not yet conceded.

We deviate from Alesina-Drazen by allowing (common) prior beliefs about $\theta_{1}$ to differ from those about $\theta_{2}$. We assume that prior beliefs are given by the distribution functions $F_{1}$ and $F_{2}$, with continuous densities $f_{1}$ and $f_{2}$. The densities $f_{1}$ and $f_{2}$ have common support $[\underline{\theta}, \bar{\theta}]$, and are bounded from above and away from zero from below. We also assume that $\bar{\theta}>\underline{\theta}>(\alpha-1 / 2) \tau$; that is, even the conceding party expects to be better off after stabilization. In the language of Fudenberg and Tirole (1986), incomplete information is "small" in the sense that it is common knowledge that both groups are interested in stabilizing the economy. ${ }^{7}$

Group $i$ 's strategy is a (measurable) function $T_{i}:[\underline{\theta}, \bar{\theta}] \rightarrow[0, \infty]$, speci-

\footnotetext{
${ }^{6}$ Monetary versions of the model are considered by Drazen and Grilli (1993) and Guidotti and Vegh (1999).

${ }^{7}$ If either this or the boundedness assumption fail, there could be a unique solution to the system described by Theorem 1 .
} 
fying for each possible value of $\theta_{i}$ the time at which group $i$ concedes if the other group has not yet given up. If it plans to concede at time $t$, and its opponent behaves according to $T_{j}$, group $i$ 's expected lifetime utility is:

$$
\begin{gathered}
V_{i}\left(t, T_{j} ; \theta_{i}\right)=\operatorname{Pr}\left\{T_{j}\left(\theta_{j}\right) \geq t\right\} \times\left[\int_{0}^{t} U_{i}^{D} e^{-r x} d x+\int_{t}^{\infty} U_{i}^{L} e^{-r x} d x\right] \\
+\int_{\left\{\theta_{j}: T\left(\theta_{j}\right)<t\right\}}\left[\int_{0}^{T_{j}\left(\theta_{j}\right)} U_{i}^{D} e^{-r x} d x\right. \\
\left.\quad+\int_{T_{j}\left(\theta_{j}\right)}^{\infty} U_{i}^{W} e^{-r x} d x\right] f_{j}\left(\theta_{j}\right) d \theta_{j} .
\end{gathered}
$$

The first term in brackets is group $i$ 's utility if group $j$ remains resisting reform at time $t$; the second term in brackets is group $i$ 's utility if group $j$ concedes at some time $T_{j}\left(\theta_{j}\right)$ before $t$.

A (Bayesian) equilibrium is a couple of strategies $\left\{T_{1}, T_{2}\right\}$ such that, if group 1 behaves according to $T_{1}$, group 2 finds it optimal to behave according to $T_{2}$ and viceversa. It is easy to see that there are equilibria without delay, in which either group 1 or group 2 concedes at time zero with probability one, while the other would wait long enough before doing so to deter the former one from deviating. The following lemma establishes some useful properties of equilibrium strategies for equilibria with delay. ${ }^{8}$

Lemma 1 If $\left\{T_{1}, T_{2}\right\}$ is an equilibrium with positive probability of delay,

(1.1) $T_{i}\left(\theta_{i}\right)=0$ on $\left[m_{i}, \bar{\theta}\right]$ for some $m_{i} \in(\underline{\theta}, \bar{\theta}]$,

(1.2) $T_{i}\left(\theta_{i}\right)$ is continuous and strictly decreasing on $\left(\tilde{\theta}_{i}, m_{i}\right]$ for some $\tilde{\theta}_{i} \in$ $[\underline{\theta}, \bar{\theta}]$ such that $\min \left\{\tilde{\theta}_{1}, \tilde{\theta}_{2}\right\}=\underline{\theta}$ and $T\left(\tilde{\theta}_{1}\right)=T\left(\tilde{\theta}_{2}\right)=\bar{T}$ for some $\bar{T}>0$ (possibly infinite), and

$$
\text { If } \bar{T}<\infty, T_{i}\left(\theta_{i}\right) \geq \bar{T} \text { on }\left[\underline{\theta}, \tilde{\theta}_{i}\right] \text {. If } \bar{T}=\infty, \tilde{\theta}_{1}=\tilde{\theta}_{2}=\underline{\theta} \text {. }
$$

(Proofs are contained in Appendix A.) Lemma 1 establishes that, along the equilibrium path, groups that suffer more heavily from pre-stabilization distortions will concede earlier.

\footnotetext{
${ }^{8}$ Strategy functions that coincide almost everywhere are payoff equivalent and are taken to represent the same strategies, so the properties described below are satisfied for a "representative" pair of functions for every strategy pair.
} 
It is convenient to define the inverse functions

$$
\Phi_{i}(t)= \begin{cases}T_{i}^{-1}(t) & \text { if } 0<t<\bar{T} \\ \min _{\theta_{i}} T_{i}^{-1}(0) & \text { if } t=0\end{cases}
$$

$\left\{\Phi_{1}(t), \Phi_{2}(t)\right\}$ represent the type of each group which concedes at time $t>0$ along the equilibrium path, and the minimum type that concedes at time 0 , where the type is given by the private cost of living with inflation. Then:

Theorem $1\left\{T_{1}, T_{2}\right\}$ is an equilibrium with positive probability of delay if and only if $\left\{\Phi_{1}, \Phi_{2}\right\}$ is a solution to:

$$
\left[-\frac{f_{j}\left(\Phi_{j}(t)\right) \Phi_{j}^{\prime}(t)}{F_{j}\left(\Phi_{j}(t)\right)}\right] \frac{2(\alpha-1 / 2) \tau}{r}=\Phi_{i}(t)-(\alpha-1 / 2) \tau
$$

$(i, j=1,2$ and $i \neq j)$ such that:

$$
\underline{\theta}<\min \left\{\Phi_{1}(0), \Phi_{2}(0)\right\} \leq \bar{\theta} \text { and } \max \left\{\Phi_{1}(0), \Phi_{2}(0)\right\}=\bar{\theta} .
$$

Moreover,

$$
\bar{T}=\infty
$$

The RHS of equation (2.1) is the cost for group $i$ of waiting another instant to concede $\left(U_{i}^{L}-U_{i}^{D}\right)$. The LHS is the expected gain for $i$ from waiting another instant to concede, which is the product of the conditional probability that group $j$ concedes at time $t$ (the term in brackets), multiplied by the gain for $i$ if $j$ concedes $\left(\int_{t}^{\infty}\left(U_{i}^{W}-U_{i}^{L}\right) e^{-r(x-t)} d x\right)$. Equation (2.2) simply states that neither group concedes at time zero with probability one and at least one of the two groups concedes at time zero with probability zero. Equation (2.3) says that groups with smaller losses from inflation will wait nearly forever before conceding.

Since $f_{1}$ and $f_{2}$ are bounded from below, the system of ordinary differential equations (2.1) is Lipschitz continuous and therefore it has a unique solution for each boundary condition defined by (2.2). That is, there are many possible equilibria with delay. Fixing, say, $\Phi_{1}(0)=\bar{\theta}$, equilibria are indexed by $\Phi_{2}(0) \in(\underline{\theta}, \bar{\theta}]$. Worse, all equilibria with delay are Bayesian perfect, since concession can occur at any moment in time, and concession effectively 
finishes the game anyway. There are also equilibria without delay that are Bayesian perfect; an example is $T\left(\theta_{1}\right)=\infty$ for all $\theta_{1}$ and $T\left(\theta_{2}\right)=0$ for all $\theta_{2}$ (or the opposite). An equilibrium like this is sustained by the following out-of-equilibrium beliefs: If group 2 has not conceded before any time $t>0$, it will concede with probability one at $t$.

In the symmetric scenario analyzed by Alesina-Drazen, selecting the symmetric equilibrium implicitly uses the boundary condition $\Phi_{1}(0)=\Phi_{2}(0)=\bar{\theta}$. In the symmetric equilibrium it is indeed the case that either increasing $\alpha$ or reducing the costs of living with inflation proportionally for both groups leads to an earlier stabilization. In the next section we propose an equilibrium selection criterion, inspired by Nalebuff and Riley (1985), that allows us to deal with the general case.

\section{A commitment-proof equilibrium}

In this section, we show that one of the two groups would benefit considerably from convincing the other that it is committed to never give in with some arbitrarily small probability. Commitment, or at least the threat of it, can be achieved by selecting ideologically motivated leaders or by adopting inflexible collective decision procedures. ${ }^{910}$ In some reform episodes of the 1980 s and 1990s in Latin America, a semblance of commitment to reform packages was achieved through the apparent delegation of economic policymaking to "technocrats" or even to multilateral lending organizations.

We proceed by "perturbing" the model with the introduction of some probability $p_{i} \epsilon$ that each group is "irrationally" committed to never give in, where $p_{i} \in[0,1], p_{1}+p_{2}>0$, and $\epsilon$ is taken to be arbitrarily small. As before, the distribution of the cost of inflation for a "rational" group is given by $F_{i}$. Let $G_{i}(x)=\left(1-p_{i} \epsilon\right) F_{i}(x)+p_{i} \epsilon$ and $g_{i}(x)=\left(1-p_{i} \epsilon\right) f_{i}(x)$. Let also

$$
K_{i} \equiv(\underline{\theta}-(\alpha-1 / 2) \tau) \ln \left(p_{j} / p_{i}\right)+\int_{\underline{\theta}}^{\bar{\theta}} \ln \left(G_{j}(x) / G_{i}(x)\right) d x .
$$

\footnotetext{
9 "Many of the attributes of rationality [...] are strategic liabilities in certain conflict situations. It may be perfectly rational to wish oneself not altogether rational, or [...] to wish for the power to suspend certain rational capabilities in particular situations" (Schelling 1960).

${ }^{10}$ Sargent's (1986) lively discussion on credibility and Reaganomics illustrates the importance, and the costs, of convincing the other of one's stubbornness.
} 
Then:

Theorem 2 In the perturbed model, if $p_{i}=0$, then in equilibrium group $i$ concedes at time zero with probability one. If $p_{1}, p_{2}>0$, the (unique) equilibrium is characterized by an analogue to equation (2.1), with $F_{i}$ and $f_{i}$ replaced by $G_{i}$ and $g_{i}$, and the following boundary condition: if $K_{i} \leq 0$, then $\Phi_{i}(0)=\bar{\theta}$; otherwise $\Phi_{i}(0)$ is given by

$$
\int_{\Phi_{i}(0)}^{\bar{\theta}}\left(g_{i}(x) / G_{i}(x)\right)(x-(\alpha-1 / 2) \tau) d x=K_{i} .
$$

By committing unilaterally to never concede, even with an arbitrarily small probability, a group is able to extract an immediate concession from the other group. If both groups are able to convince the other that they are "irrationally" committed to never give up with some positive probability, then we obtain a unique equilibrium that is similar to those described by Theorem 1. (That is, there are no equilibria without delay if $p_{1}, p_{2}>0$.) Now by letting $\epsilon$ go to zero for $p_{1}=p_{2}>0$, we can in fact select a unique equilibrium in the unperturbed model. We refer to this as the commitmentproof equilibrium. ${ }^{11}$

Since $f_{1}$ and $f_{2}$ are bounded from above and away from zero from below,

$$
\lim _{\epsilon \downarrow 0} \int_{\underline{\theta}}^{\bar{\theta}} \ln \left(G_{i}(x) / G_{j}(x)\right) d x=\int_{\underline{\theta}}^{\bar{\theta}} \ln \left(F_{i}(x) / F_{j}(x)\right) d x .
$$

Thus, in the commitment-proof equilibrium,

$$
\Phi_{i}(0)<\bar{\theta} \text { if and only if } \int_{\underline{\theta}}^{\bar{\theta}} \ln \left(F_{j}(x) / F_{i}(x)\right) d x>0 ;
$$

in this case $\Phi_{i}(0)$ is given by

$$
\int_{\Phi_{i}(0)}^{\bar{\theta}}\left(f_{i}(x) / F_{i}(x)\right)(x-(\alpha-1 / 2) \tau) d x=\int_{\underline{\theta}}^{\bar{\theta}} \ln \left(F_{j}(x) / F_{i}(x)\right) d x .
$$

It follows that one party will concede at time zero with positive probability, unless pre-stabilization welfare losses are "very close" in stochastic terms for the two groups, in the sense that $\int_{\underline{\theta}}^{\bar{\theta}} \ln \left(F_{1}(x) / F_{2}(x)\right) d x=0$. Moreover,

\footnotetext{
${ }^{11}$ Note that a unique selection can be made even if $p_{1} \neq p_{2}$ is a more appropriate assumption; the boundary condition used to select an equilibrium changes continuously with $p_{1} / p_{2}$.
} 
if pre-stabilization welfare losses of one party exhibit first-order stochastic dominance over the losses of the other, then the former party concedes at time zero with positive probability.

Inspecting the conditions satisfied by the commitment-proof equilibrium, we can see that, ceteris paribus, an outward shift of both distributions of losses to $\tilde{F}_{1}, \tilde{F}_{2}$ with $\tilde{F}_{1}\left(\theta_{1}-\kappa\right)=F_{1}\left(\theta_{1}\right)$ and $\tilde{F}_{2}\left(\theta_{2}-\kappa\right)=F_{2}\left(\theta_{2}\right)$ for some $\kappa>0$, leads to an increase in $\min _{i} \Phi_{i}(0)$ (as long as $\min _{i} \Phi_{i}(0)<\bar{\theta}$ ). That is, if inflation becomes proportionally more painful for both parties, the probability of immediate reform increases. Finally, and rather surprisingly, if $\alpha$ increases, $\Phi_{i}(0)$ should decrease (as long as $\min _{i} \Phi_{i}(0)<\bar{\theta}$ ). That is, wider distributional implications of reform increase the probability of immediate reform.

This last result can be related to the increased "willingness to fight" of the party that does not concede at time 0 convincing the marginal type or types of the other party that it is not worth entering the conflict. This argument suggests that, if $\alpha$ increases, the expected time of stabilization may be delayed nonetheless due to the increased willingness to fight of the types of both parties that do enter the conflict. We explore this and other comparative static exercises on the timing of stabilization in the context of a specific functional form in the next section.

\section{Comparative statics}

We consider the family of linear densities with support $[\underline{\theta}, \bar{\theta}]=[1,2]$. Thus:

$$
f_{i}\left(\theta_{i}\right)=2 \lambda_{i}\left(\theta_{i}-1\right)+1-\lambda_{i}
$$

with $-1<\lambda_{i}<1$. Note that $\lambda_{i}=0$ corresponds to the uniform density, and $\lambda_{1}<\lambda_{2}$ implies that the losses of party 2 exhibits first order stochastic dominance over the losses of party 1 . We normalize $\tau$ to one; this is equivalent to assuming that, if reform plans are very unequal ( $\alpha$ close to one), a party with the lowest possible losses from inflation will gain almost nothing from conceding, while a party with the highest possible losses will cut its losses by more than half by conceding. Finally, we set $r=0.04$.

Using Theorem 1 and the boundary condition derived in Section 3, we 
have that, if $\lambda_{1} \leq \lambda_{2}$,

$$
-\left(\frac{2 \gamma_{j}\left(\Phi_{j}(t)-1\right)+1}{\gamma_{j}\left(\Phi_{j}(t)-1\right)^{2}+\left(\Phi_{j}(t)-1\right)}\right)(50 \alpha-25) \Phi_{j}^{\prime}(t)=\Phi_{i}(t)-\alpha+1 / 2
$$

where $\gamma_{j}=\lambda_{j} /\left(1-\lambda_{j}\right)$, for $i=1,2, j \neq i$, with $\Phi_{1}(0)=2$ and $\Phi_{2}(0)$ given by

$$
\begin{aligned}
\int_{\Phi_{2}(0)}^{2}\left(\frac{2 \gamma_{2}(x-1)+1}{\gamma_{2}(x-1)^{2}+(x-1)}\right)(x-\alpha & +1 / 2) d x \\
& =\int_{1}^{2} \ln \left(\frac{\gamma_{2}(x-1)+1}{\gamma_{1}(x-1)+1}\right) d x
\end{aligned}
$$

Using $\Phi_{2}(0)$, we can calculate the probability of immediate agreement as

$\operatorname{Pr}\left\{T_{2}\left(\theta_{2}\right)=0\right\}=1-F_{2}\left(\Phi_{2}(0)\right)=1-\lambda_{2}\left(\Phi_{2}(0)-1\right)^{2}-\left(1-\lambda_{2}\right)\left(\Phi_{2}(0)-1\right)$.

We use the system of differential equations given by (3.1) and the implicit boundary condition (3.2) to estimate also the expected time of stabilization and the expected welfare of both parties under a variety of scenarios (see Appendix B for a description of numerical methods).

Tables 1.1 to 1.3 report the results for the probability of immediate agreement and the expected time of stabilization. Given our assumption on $r$, we can interpret the unit of time as a year. Thus, the expected delay of stabilization goes from $19 \frac{1}{2}$ months (Table 3.1, bottom left) to 7 years (Table 3.3, bottom right), while the probability of immediate agreement goes from 0 to $29 \%$. In each table, the diagonal represents the case of ex ante symmetry between the two parties, with expected losses from inflation increasing as we go down or right. If the expected losses increase for party 2 (the party already disadvantaged in terms of expected losses), then the expected delay of stabilization is reduced and the probability of an immediate agreement increases. The opposite happens if the expected losses increase for party 1 . Increasing the expected losses from inflation to both parties over the diagonal leads to an earlier expected stabilization. Out of the diagonal, there is no clear cut result. Finally, holding fixed the expected losses for both parties but increasing the degree of polarization $\alpha$ leads to an increase in the probability of an immediate agreement (outside of the diagonal) but to a longer expected delay. This provides support to the intuitive argument at the end of the previous section. 
Table 1.1: Probability of immediate agreement and expected time of stabilization $(\alpha=5 / 8)$

\begin{tabular}{|c|ccccccc|}
\hline$\lambda_{2} \backslash \lambda_{1}$ & $-1 / 2$ & $-1 / 3$ & $-1 / 6$ & 0 & $1 / 6$ & $1 / 3$ & $1 / 2$ \\
\hline \multirow{2}{*}{$-1 / 2$} & 0 & & & & & & \\
& 2.223 & & & & & & \\
$-1 / 3$ & 0.034 & 0 & & & & & \\
& 2.139 & 2.173 & & & & & \\
$-1 / 6$ & 0.072 & 0.037 & 0 & & & & \\
& 2.049 & 2.085 & 2.126 & & & & \\
0 & 0.112 & 0.079 & 0.042 & 0 & & & \\
& 1.954 & 1.990 & 2.032 & 2.082 & & & \\
$1 / 6$ & 0.155 & 0.122 & 0.086 & 0.046 & 0 & & \\
& 1.852 & 1.890 & 1.933 & 1.982 & 2.041 & & \\
$1 / 3$ & 0.202 & 0.171 & 0.136 & 0.098 & 0.052 & 0 & \\
& 1.744 & 1.781 & 1.825 & 1.873 & 1.932 & 2.003 & \\
$1 / 2$ & 0.253 & 0.224 & 0.192 & 0.154 & 0.112 & 0.062 & 0 \\
& 1.628 & 1.664 & 1.705 & 1.754 & 1.811 & 1.881 & 1.969 \\
\hline
\end{tabular}

Table 1.2: Probability of immediate agreement and expected time of stabilization $(\alpha=6 / 8)$

\begin{tabular}{|c|ccccccc|}
\hline$\lambda_{2} \backslash \lambda_{1}$ & $-1 / 2$ & $-1 / 3$ & $-1 / 6$ & 0 & $1 / 6$ & $1 / 3$ & $1 / 2$ \\
\hline$-1 / 2$ & 0 & & & & & & \\
& 4.900 & & & & & & \\
$-1 / 3$ & 0.037 & 0 & & & & & \\
& 4.700 & 4.777 & & & & & \\
$-1 / 6$ & 0.077 & 0.040 & 0 & & & & \\
& 4.491 & 4.572 & 4.663 & & & & \\
0 & 0.120 & 0.084 & 0.045 & 0 & & & \\
& 4.268 & 4.352 & 4.445 & 4.556 & & & \\
$1 / 6$ & 0.166 & 0.132 & 0.093 & 0.049 & 0 & & \\
& 4.029 & 4.114 & 4.212 & 4.325 & 4.458 & & \\
$1 / 3$ & 0.215 & 0.183 & 0.146 & 0.104 & 0.056 & 0 & \\
& 3.780 & 3.860 & 3.959 & 4.073 & 4.205 & 4.367 & \\
& 0.272 & 0.240 & 0.205 & 0.165 & 0.119 & 0.066 & 0 \\
& 3.501 & 3.585 & 3.681 & 3.793 & 3.927 & 4.083 & 4.284 \\
\hline
\end{tabular}


Table 1.3: Probability of immediate agreement and expected time of stabilization $(\alpha=7 / 8)$

\begin{tabular}{|c|ccccccc|}
\hline$\lambda_{2} \backslash \lambda_{1}$ & $-1 / 2$ & $-1 / 3$ & $-1 / 6$ & 0 & $1 / 6$ & $1 / 3$ & $1 / 2$ \\
\hline$-1 / 2$ & 0 & & & & & & \\
& 8.190 & & & & & & \\
$-1 / 3$ & 0.040 & 0 & & & & & \\
& 7.835 & 7.963 & & & & & \\
$-1 / 6$ & 0.083 & 0.043 & 0 & & & & \\
& 7.461 & 7.596 & 7.750 & & & & \\
0 & 0.130 & 0.091 & 0.048 & 0 & & & \\
& 7.059 & 7.203 & 7.366 & 7.552 & & & \\
$1 / 6$ & 0.179 & 0.142 & 0.100 & 0.053 & 0 & & \\
& 6.640 & 6.783 & 6.952 & 7.145 & 7.369 & & \\
$1 / 3$ & 0.232 & 0.197 & 0.157 & 0.112 & 0.060 & 0 & \\
& 6.188 & 6.333 & 6.500 & 6.699 & 6.928 & 7.202 & \\
$1 / 2$ & 0.291 & 0.257 & 0.220 & 0.178 & 0.129 & 0.070 & 0 \\
& 5.702 & 5.848 & 6.011 & 6.202 & 6.428 & 6.707 & 7.049 \\
\hline
\end{tabular}

Tables 2.1 to 2.3 provide estimations of the expected costs of the conflict for parties 1 and 2. From our assumptions, the sum of expected welfare of party 1 and party 2 would be maximized if there were an immediate agreement at time 0 . Thus, the maximum possible total welfare is $-\tau / r=-25$, representing the purely economic cost of financing the government deficit. Letting $E V_{i}$ be the expected welfare of party $i$, we compute the political cost of conflict for party $i$ as

$$
100\left(\left|E V_{i}\right| / 25-1 / 2\right) \text {. }
$$

This represents the expected loss of welfare to party $i$ of entering into the conflict instead of splitting in half the economic cost of the government deficit, expressed as a percentage of the economic cost of the deficit. From the individual rationality constraint:

$$
E V_{i} \geq-\alpha \tau / r=-25 \alpha,
$$

guaranteeing that a party will not be better off by surrendering at time 0 rather than entering the conflict, we can obtain an upper bound of $100(2 \alpha-1)$ 
for the total expected political cost as a percentage of the economic cost. Thus, in Table 2.1 the upper bound for the total political cost is $25 \%$ of the economic cost, in Table 2.2 it is $50 \%$, and in Table 2.3 it is $75 \%$. The total political cost in our estimations goes from $16.53 \%$ (Table 2.1, bottom left) to $66.42 \%$ (Table 2.3 , bottom right).

Looking at each table from 2.1 to 2.3 , we can see that increasing the inflation losses for both parties increase the total political cost along the diagonal. That is, the fact that inflation lasts less time does not compensate the fact that it is more painful. ${ }^{12}$ Outside the diagonal, the total political cost may increase or decrease, but it generally decreases when inflation losses increase for both parties. When inflation losses increase only for party 2 , the total expected political cost is reduced, while the opposite happens when inflation losses increase only for party 1 . Finally, increasing $\alpha$ while holding inflation losses constant always makes both parties worse off.

Table 2.1: Expected political costs for party 1 and party $2(\alpha=5 / 8)$

\begin{tabular}{|c|rrrrrrr|}
\hline$\lambda_{2} \backslash \lambda_{1}$ & $-1 / 2$ & $-1 / 3$ & $-1 / 6$ & 0 & $1 / 6$ & $1 / 3$ & $1 / 2$ \\
\hline$-1 / 2$ & 10.85 & & & & & & \\
& 10.85 & & & & & & \\
$-1 / 3$ & 10.03 & 10.86 & & & & & \\
& 10.97 & 10.86 & & & & & \\
$-1 / 6$ & 9.16 & 9.97 & 10.89 & & & & \\
& 11.09 & 11.00 & 10.89 & & & & \\
0 & 8.23 & 9.00 & 9.90 & 10.94 & & & \\
& 11.22 & 11.14 & 11.04 & 10.94 & & & \\
$1 / 6$ & 7.21 & 7.97 & 8.85 & 9.84 & 11.00 & & \\
& 11.35 & 11.28 & 11.20 & 11.11 & 11.00 & & \\
$1 / 3$ & 6.11 & 6.84 & 7.68 & 8.62 & 9.75 & 11.08 & \\
& 11.48 & 11.42 & 11.35 & 11.28 & 11.19 & 11.08 & \\
$1 / 2$ & 4.91 & 5.59 & 6.38 & 7.29 & 8.34 & 9.61 & 11.17 \\
& 11.62 & 11.57 & 11.51 & 11.45 & 11.37 & 11.28 & 11.17 \\
\hline
\end{tabular}

\footnotetext{
${ }^{12}$ Simulations by Drazen and Grilli (1993) have found that for low levels of inflation costs the reverse may be true.
} 
Table 2.2: Expected political costs

for party 1 and party $2(\alpha=6 / 8)$

\begin{tabular}{|c|rrrrrrr|}
\hline$\lambda_{2} \backslash \lambda_{1}$ & $-1 / 2$ & $-1 / 3$ & $-1 / 6$ & 0 & $1 / 6$ & $1 / 3$ & $1 / 2$ \\
\hline \multirow{2}{*}{$-1 / 2$} & 21.54 & & & & & & \\
& 21.54 & & & & & & \\
$-1 / 3$ & 19.77 & 21.56 & & & & & \\
& 21.82 & 21.56 & & & & & \\
$-1 / 6$ & 17.92 & 19.67 & 21.63 & & & & \\
& 22.08 & 21.87 & 21.63 & & & & \\
0 & 15.92 & 17.62 & 19.51 & 21.73 & & & \\
& 22.36 & 22.18 & 21.97 & 21.73 & & & \\
$1 / 6$ & 13.74 & 15.38 & 17.24 & 19.38 & 21.87 & & \\
& 22.64 & 22.49 & 22.31 & 22.11 & 21.87 & & \\
$1 / 3$ & 11.45 & 12.95 & 14.76 & 16.81 & 19.19 & 22.03 & \\
& 22.92 & 22.80 & 22.65 & 22.48 & 22.28 & 22.03 & \\
$1 / 2$ & 8.82 & 10.30 & 11.99 & 13.93 & 16.23 & 18.89 & 22.22 \\
& 23.22 & 23.11 & 22.99 & 22.85 & 22.68 & 22.48 & 22.22 \\
\hline
\end{tabular}

Table 2.3: Expected political costs for party 1 and party $2(\alpha=7 / 8)$

\begin{tabular}{|c|ccccccc|}
\hline$\lambda_{2} \backslash \lambda_{1}$ & $-1 / 2$ & $-1 / 3$ & $-1 / 6$ & 0 & $1 / 6$ & $1 / 3$ & $1 / 2$ \\
\hline$-1 / 2$ & 32.09 & & & & & & \\
& 32.09 & & & & & & \\
$-1 / 3$ & 29.24 & 32.13 & & & & & \\
& 32.56 & 32.13 & & & & & \\
$-1 / 6$ & 26.24 & 29.06 & 32.25 & & & & \\
& 33.01 & 32.66 & 32.25 & & & & \\
0 & 22.97 & 25.75 & 28.87 & 32.43 & & & \\
& 33.47 & 33.17 & 32.83 & 32.43 & & & \\
$1 / 6$ & 19.55 & 22.17 & 25.21 & 28.67 & 32.65 & & \\
& 33.92 & 33.67 & 33.38 & 33.05 & 32.65 & & \\
$1 / 3$ & 15.79 & 18.30 & 21.18 & 24.53 & 28.37 & 32.92 & \\
& 34.38 & 34.17 & 33.93 & 33.64 & 33.31 & 32.92 & \\
& 11.69 & 14.09 & 16.78 & 19.89 & 23.51 & 27.90 & 33.21 \\
& 34.85 & 34.67 & 34.47 & 34.24 & 33.96 & 33.63 & 33.21 \\
\hline
\end{tabular}




\section{$5 \quad$ Large asymmetries}

In this section, we consider a situation is which it is common knowledge that the lowest possible cost inflation for one party is larger than for the other, even if the cost of inflation is private information. We interpret this situation as reflecting very accurate common information in relation to the size of the asymmetries in inflation costs.

Formally, we modify the model so that now the support of the distribution of $\theta_{i}$ is $\left[\underline{\theta}_{i}, \bar{\theta}_{i}\right]$ for $i=1,2$, and

$$
\underline{\theta}_{2}>\underline{\theta}_{1}>(\alpha-1 / 2) \tau
$$

We can imagine that party 2 represents the poor, and that it is believed that in the best possible scenario for both rich and poor, the poor cannot be better protected from inflation than the rich.

In this version of the model, we still have equilibria without delay and (many) equilibria with positive probability of delay. Equilibria with delay are characterized by equation (2.1) and an analogue of equation (2.2):

$$
\underline{\theta}_{i}<\Phi_{i}(0) \leq \bar{\theta}_{i} \text { for } i=1,2 \text {, and } \Phi_{1}(0)=\bar{\theta}_{1} \text { or } \Phi_{2}(0)=\bar{\theta}_{2} \text { (or both). }
$$

Perturbing this model, as in Section 3, we obtain a result similar to Theorem 2, except that now $\Phi_{i}(0)<\bar{\theta}$ if and only if

$$
\begin{aligned}
K_{i} \equiv\left(\underline{\theta}_{j}-(\alpha-1 / 2) \tau\right) \ln \left(p_{j} \epsilon\right)- & \left(\underline{\theta}_{i}-(\alpha-1 / 2) \tau\right) \ln \left(p_{i} \epsilon\right) \\
& +\int_{\underline{\theta}_{j}}^{\bar{\theta}_{j}} \ln G_{j}(x) d x-\int_{\underline{\theta}_{i}}^{\bar{\theta}_{i}} \ln G_{i}(x) d x>0 .
\end{aligned}
$$

Letting $\epsilon$ go to zero for $p_{1}, p_{2}>0$, we get that $K_{2}$ goes to $-\infty$. That is, in the unique equilibrium of the perturbed model, party 2 concedes at time zero with probability arbitrarily close to one as $\epsilon$ go to zero. It follows that, in the commitment-proof equilibrium, party 2 concedes at time zero with probability one. Accurate information leads to no delay at all!

If the probability of commitment is not zero, there will be some probability of delay. This is perhaps a more satisfying assumption to the extent that then the probability of delay changes continuously with the support of the prior beliefs. A positive probability of delay will also result if the distributive consequences of reform are so dire that $(\alpha-1 / 2) \tau>\underline{\theta}_{2}>\underline{\theta}_{1}$, so that 
with some probability both parties will be unwilling to give up. In that case, from the work of Fudenberg and Tirole (1986), we know that the equilibrium will be unique and will generally involve a positive probability of immediate concession.

\section{Final remarks}

We argue in this paper that asymmetries in the losses occasioned by prestabilization distortions to different political groups may lead to a sooner end of episodes of delayed stabilization. A number of economic reform episodes in Latin America in the last two decades seem to fit this pattern. In terms of understanding those episodes, the model points to the need of collecting evidence on the distribution of the cost of pre-stabilization distortions in those cases. We also argue that social polarization, in the sense of wider distributional implications of the available reform plans, makes conflicts over stabilization less likely, but contributes to a longer delay if a conflict breaks up.

From a broader perspective, our paper, as well as related literature stemming from Alesina-Drazen (1991), emphasizes the role in stabilization delay of the absence or weakness of institutions of conflict management that allow fiscal shocks to develop into distributional conflicts. Recent contributions by Rodrik (1999) and by Acemoglu et al. (2003) show that in fact weak institutions account for a large fraction of the macroeconomic volatility and dismal growth performance of many countries in Latin America and elsewhere. The wave of economic reforms of the 1980s and 1990s does not seem to have done much in terms of strengthening institutions for conflict management. Consistent with the "seesaw hypothesis" of Acemoglu et al. (2003), market-oriented reforms were often accompanied by new ways to engage into traditional predatory and redistributive activities. ${ }^{13}$ Thus, fiscal shocks occasioned by external circumstances may in the future trigger again the inconsistent policies that characterized the delayed stabilizations of the past.

\footnotetext{
${ }^{13}$ In the case of Peru in the 1990s, for instance, Bowen and Hollinger (2003) provide some examples of creative use of the judicial system and the tax agency for extortion, predation and redistribution.
} 
A particular obstacle for conflict management emphasized in this paper is the absence of accurate information regarding the costs of delayed reform. This paper, as a large part of the political economy literature, is silent on how the relevant agents acquire and aggregate information. Incorporating adequate microfoundations with respect to information acquisition and aggregation in this and other political economy models is a challenge for future research. 


\section{Appendix A: Proofs}

A rigorous demonstration for most of the content of Lemma 1 and Theorem 1 is provided by Fudenberg and Tirole (1986); here the proof is only sketched. The proof of Theorem 2 follows Nalebuff and Riley (1985).

\section{Proof of Lemma 1:}

If there is positive probability of delay, there is some $\bar{T}>0$ (possibly infinite) such that for every $t<\bar{T}$ there is some positive probability that neither party has conceded, and the probability that neither party has conceded at or before $\bar{T}$ is zero. $T_{i}$ is nonincreasing for the set of types such that $T_{i}\left(\theta_{i}\right)<\bar{T}$, and this set must be some interval $\left(\tilde{\theta}_{i}, \bar{\theta}\right]$, because increasing $\theta_{i}$ decreases the payoff to keep fighting but does not change the payoff to conceding. $T_{i}$ must also be gapless on $[0, \bar{T})$ : If there is a gap $\left[\beta^{\prime}, \beta\right) \subset[0, \bar{T})$ in $T_{i}$ (that is, an interval over which group $i$ concedes with probability zero), then there must be a gap $\left(\beta^{\prime}, \beta\right)$ in $T_{j}$ because for any $\theta_{j}$ it would be preferable to concede at time $\beta^{\prime}$ than at $\left(\beta^{\prime}, \beta\right)$. But then any type of group $i$ planning to concede at or near $\beta$ would be better off conceding at time $\left(\beta^{\prime}+\beta\right) / 2$. Furthermore, $T_{i}$ must be atomless on $(0, \bar{T})$ : If there is some nonnegligible probability of group $i$ conceding at time $0<\eta<\bar{T}$ (a mass of types $\theta_{i}$ conceding at time $\eta)$, then there will be some interval $(\eta-\epsilon, \eta)$ such that in that interval group $j$ will prefer to wait for the discontinuous jump in the probability of group $i$ conceding. But this would create a gap on $(0, \bar{T})$. By the same reasoning, if $\bar{T}$ is finite, $T_{i}$ must be atomless on $(0, \bar{T}]$.

The previous discussion establishes that $T_{i}$ is continuous and strictly decreasing on $\left(\tilde{\theta}_{i}, m_{i}\right]$, where $m_{i}$ is the lowest type that concedes at time 0 . Moreover, if $\bar{T}$ is finite, it follows that at least one party concedes before $\bar{T}$ with probability one, so $\min \left\{\tilde{\theta}_{1}, \tilde{\theta}_{2}\right\}=\underline{\theta}$, and if one party does not concede with probability one before $\bar{T}$, then $T\left(\theta_{i}\right) \geq \bar{T}$ on $\left[\underline{\theta}, \tilde{\theta}_{i}\right]$. If $\bar{T}$ is infinite, then $\tilde{\theta}_{1}=\tilde{\theta}_{2}=\underline{\theta}$ because otherwise at least one party would concede at $\infty$ with positive probability. But then the probability of concession by this party after $t$ would get arbitrarily close to zero as $t$ increases, and there would be some time $t^{\prime}$ such that the other party would prefer to concede for any prestabilization welfare loss smaller than or equal to $\underline{\theta}$ rather than keep resisting nearly forever. 
Proof of Theorem 1:

We prove necessity; the proof of sufficiency is straightforward. From the properties of $T_{i}$ given by Lemma 1 it follows that its inverse $\Phi_{i}$ is continuous and strictly increasing. Everywhere differentiability can be established following Lemma 1(iv) in Fudenberg and Tirole (1986). Equation (2.1) then follows from differentiating $V_{i}\left(t, T_{j} ; \theta_{i}\right)$ with respect to $t$ and making the derivative equal to zero at $T_{i}\left(\theta_{i}\right)=t\left(\right.$ or $\left.\Phi_{i}(t)=\theta_{i}\right)$. Where this derivative positive, group $i$ would prefer to wait longer to concede, while were it negative, group $i$ would prefer to concede before $T_{i}\left(\theta_{i}\right)$.

Equation (2.2) is proved by contradiction. If both groups were conceding at time 0 with positive probability, any group would be better off by waiting infinitesimally to see if its rival concedes immediately. If any group were conceding at time 0 with probability one, there would not be a positive probability of delay.

To show that the system of ordinary differential equations given by $(2.1)$ has a (unique) solution for each boundary condition satisfying (2.2), note that the mapping $\phi:(\underline{\theta}, \bar{\theta})^{2} \rightarrow \Re^{2}$ from $\Phi=\left(\Phi_{1}, \Phi_{2}\right)$ to $\dot{\Phi}=\left(\dot{\Phi}_{1}, \dot{\Phi}_{2}\right)$ (the time derivatives) given by (2.1) is Lipschitz continuous. Thus, it has a unique solution through every $\Phi \in(\underline{\theta}, \bar{\theta})^{2}$; that is, a function $\xi(\cdot, \Phi): J \rightarrow \Re^{2}$ where $J$ is an open interval containing $t=0$ such that $\xi(0, \Phi)=\Phi$ and $D_{t} \xi(t, \Phi)=\phi(\xi(t, \Phi))$. Moreover, the solution is continuous in $t$ and $\Phi$ (see e.g. Hirsch and Smale 1974). Since $f_{1}, f_{2}$ are bounded, we can easily extend the dominion of $\phi$ to include the endpoint $\bar{\theta}$, so we have a unique solution for every $\Phi$ satisfying (2.2). Finally, since $\dot{\Phi}_{i}<0$ for $\Phi_{i} \in(\underline{\theta}, \bar{\theta}]$ and $\Phi_{j} \in[\underline{\theta}, \bar{\theta}]$, with $\lim _{\Phi_{i} \downarrow \underline{\theta}} \dot{\Phi}_{i}=0$, and every solution must lie in the compact set $[\underline{\theta}, \bar{\theta}]^{2}$, then $\xi(t, \Phi)$ is defined for all $t \geq 0$, and in fact as $t$ goes to $\infty, \xi(t, \Phi)$ goes to the point $(\underline{\theta}, \underline{\theta})$. That is, in equilibrium the last time of concession is the same for both parties and is infinite.

\section{Proof of Theorem 2:}

Note first that, if $p_{i}>0$, there is no equilibrium in which party $i$ concedes at time 0 with probability one (conditional on party $i$ being rational). In any such equilibria, party $j$ would be persuaded that party $i$ is irrational if concession does not occur at time 0 , and then, conditional on being rational, 
it would concede with probability one after some arbitrarily small interval. ${ }^{14}$ But then party $i$ would have an incentive to wait until rational types of party $j$ concede. Thus, in the perturbed model, if $p_{1}, p_{2}>0$, there are no equilibria in which either type, conditional on being rational, concedes at time zero. Moreover, if $p_{i}=0$ and $p_{j}>0$, there is still an equilibrium without delay in which party $i$ concedes at time zero with probability one and party $j$ never concedes.

To investigate equilibria with delay, using arguments similar to those of Lemma 1 and Theorem 1, we obtain an expression similar to equation (2.1), that we can write as:

$$
-\left[\frac{g_{j}\left(\Phi_{j}(t)\right)}{G_{j}\left(\Phi_{j}(t)\right)}\right] \frac{2(\alpha-1 / 2) \tau r^{-1}}{\Phi_{i}(t)-(\alpha-1 / 2) \tau} \frac{\partial \Phi_{j}(t)}{\partial t}=1 .
$$

Changing variables and integrating in $\theta_{j}$, we obtain a condition on the last concession time for a rational type of party $j$ :

$$
\begin{aligned}
T_{j}(\underline{\theta})= & \int_{\underline{\theta}}^{\bar{\theta}}\left[\frac{g_{j}(x)}{G_{j}(x)}\right] \frac{2(\alpha-1 / 2) \tau r^{-1}}{\Phi_{i}\left(T_{j}(x)\right)-(\alpha-1 / 2) \tau} d x \\
& <\int_{\underline{\theta}}^{\bar{\theta}}\left[\frac{g_{j}(x)}{G_{j}(x)}\right] \frac{2(\alpha-1 / 2) \tau r^{-1}}{\underline{\theta}-(\alpha-1 / 2) \tau} d x=-\ln \left(p_{i} \epsilon\right) \times \frac{2(\alpha-1 / 2) \tau r^{-1}}{\underline{\theta}-(\alpha-1 / 2) \tau} .
\end{aligned}
$$

That is, if $p_{i}>0, T_{j}(\bar{\theta})<\infty$. Now, $T_{j}(\underline{\theta})=T_{i}(\underline{\theta})$, because if group $i$ will not concede after some finite time, then group $j$ has nothing to gain by waiting any longer, and viceversa.

Using (A.1):

$$
\left[\frac{g_{2}\left(\Phi_{2}(t)\right)}{G_{2}\left(\Phi_{2}(t)\right)}\right]\left(\Phi_{2}(t)-(\alpha-1 / 2) \tau\right) \frac{\partial \Phi_{2}(t)}{\partial \Phi_{1}(t)}=\left[\frac{g_{1}\left(\Phi_{1}(t)\right)}{G_{1}\left(\Phi_{1}(t)\right)}\right]\left(\Phi_{1}(t)-(\alpha-1 / 2) \tau\right) .
$$

This implicitly defines a first order differential equation for $\theta_{2}$ as a function of $\theta_{1}$. Consider the following, strictly decreasing function:

$$
H_{i}\left(\theta_{i}\right)=\int_{\theta_{i}}^{\sigma_{i}}\left(g_{i}(x) / G_{i}(x)\right)(x-(\alpha-1 / 2) \tau) d x
$$

\footnotetext{
${ }^{14}$ Strictly speaking, there is no best response for party $j$ which is enough to prove nonexistence of equilibrium.
} 
where $\sigma_{i}$ is some fixed real number in $(\underline{\theta}, \bar{\theta})$. Using the definition of $H$ and the previous equation, we obtain a mapping from the type of group 1 that concedes at a given time to the type of group 2 that concedes at the same time:

$$
H_{2}\left(\theta_{2}\right)=H_{1}\left(\theta_{1}\right)+c .
$$

where $c$ is an integration constant. Since the last concession time is the same for both groups, we have $c=H_{2}(\underline{\theta})-H_{1}(\underline{\theta})$. Thus

$$
H_{2}\left(\Phi_{2}(0)\right)-H_{2}(\bar{\theta})=H_{1}\left(\Phi_{1}(0)\right)-H_{1}(\bar{\theta})+M,
$$

where $M \equiv H_{1}(\bar{\theta})-H_{1}(\underline{\theta})-H_{2}(\bar{\theta})+H_{2}(\underline{\theta})$. A condition similar to (2.2) still holds in the perturbed model. It follows that $\Phi_{2}(0)<\bar{\theta}$ and $\Phi_{1}(0)=\bar{\theta}$ if and only if $M>0$, and $\Phi_{1}(0)<\bar{\theta}$ and $\Phi_{2}(0)=\bar{\theta}$ if and only if $M<0$.

To find $M$, integrating by parts in (A.2) we get:

$$
H_{i}\left(\theta_{i}\right)=\left[( x - ( \alpha - 1 / 2 ) \tau ) \operatorname { l n } ( G _ { i } ( x ) ) \left[_{x=\theta_{i}}^{x=\sigma_{i}}-\int_{\theta_{i}}^{\sigma_{i}} \ln \left(G_{i}(x)\right) d x .\right.\right.
$$

Thus, if $p_{1}, p_{2}>0$,

$$
M=(\underline{\theta}-(\alpha-1 / 2) \tau) \ln \left(p_{1} / p_{2}\right)+\int_{\underline{\theta}}^{\bar{\theta}} \ln \left(G_{1}(x) / G_{2}(x)\right) d x .
$$

If, say, $M>0$, using (A.2) and (A.3) we obtain an expression to compute $\Phi_{2}(0)$ :

$$
\int_{\Phi_{2}(0)}^{\bar{\theta}}\left(g_{2}(x) / G_{2}(x)\right)(x-(\alpha-1 / 2) \tau) d x=M,
$$

and we can compute $\Phi_{1}(0)$ similarly if $M<0$. (Note that the integral in the LHS is strictly decreasing in $\Phi_{2}(0)$, and that it grows without bound as $\Phi_{2}(0)$ approaches $\underline{\theta}$, which guarantees existence and uniqueness.) Finally, if $p_{1}>0$ and $p_{2}=0, M=\infty$ and then there is no solution to (A.3) for $\Phi_{2}(0)>\underline{\theta}$; that is, there is no equilibrium with delay. Similarly, if $p_{1}=0$ and $p_{2}>0$, $M=-\infty$ and an equivalent argument holds.

Proof of claims in Section 5:

The claims in Section 5 can be verified by following the steps of the proofs of Theorems 1 and 2, substituting $\underline{\theta}_{i}$ for $\underline{\theta}$ and $\bar{\theta}_{i}$ for $\bar{\theta}$ where appropriate, 
except that now equation (A.4) is replaced by

$$
\begin{aligned}
M=\left(\underline{\theta}_{1}-(\alpha-1 / 2) \tau\right) \ln \left(p_{1} \epsilon\right)-\left(\underline{\theta}_{2}\right. & -(\alpha-1 / 2) \tau) \ln \left(p_{2} \epsilon\right) \\
& +\int_{\underline{\theta}_{1}}^{\bar{\theta}_{1}} \ln G_{1}(x) d x-\int_{\underline{\theta}_{2}}^{\bar{\theta}_{2}} \ln G_{2}(x) d x .
\end{aligned}
$$

\section{Appendix B: Numerical methods}

In order to solve the system given by (3.1) and (3.2) we employ the fourthorder Runge-Kutta method (see e.g. Robertson 1991). Here the step size is $h=0.01$, the time span [0,200] and the number of steps $n=200 / h$. Rewriting (3.1) as

$$
\phi_{i}^{\prime}(t)=\frac{\left(\phi_{j}(t)-\alpha+\frac{1}{2}\right)\left(\left(1-\phi_{i}(t)\right)-\gamma_{i}\left(1-\phi_{i}(t)\right)^{2}\right)}{\left(2 \gamma_{i}\left(\phi_{i}(t)-1\right)+1\right)(50 \alpha-25)} \equiv \psi_{i}\left(t, \phi_{i}, \phi_{j}\right),
$$

for $i=1,2, j \neq i$, allows us to implement the method in the following way:

$$
\phi_{i(k+1)}=\phi_{i k}+\frac{1}{6} \mu_{i k 1}+\frac{1}{3} \mu_{i k 2}+\frac{1}{3} \mu_{i k 3}+\frac{1}{6} \mu_{i k 4},
$$

where

$$
\begin{aligned}
& \mu_{i k 1}=h \psi_{i}\left(t_{k}, \phi_{i k}, \phi_{j k}\right), \\
& \mu_{i k 2}=h \psi_{i}\left(t_{k}+\frac{1}{2} h, \phi_{i k}+\frac{1}{2} \mu_{i k 1}, \phi_{j k}+\frac{1}{2} \mu_{j k 1}\right), \\
& \mu_{i k 3}=h \psi_{i}\left(t_{k}+\frac{1}{2} h, \phi_{i k}+\frac{1}{2} \mu_{i k 2}, \phi_{j k}+\frac{1}{2} \mu_{j k 2}\right), \\
& \mu_{i k 4}=h \psi_{i}\left(t_{k}+h, \phi_{i k}+\mu_{i k 3}, \phi_{j k}+\mu_{j k 3}\right),
\end{aligned}
$$

with $\phi_{10}=2$ and $\phi_{20}$ given implicitly by (3.2). With this data we can approximate the expected time of stabilization and the expected welfare of both parties.

\section{Expected time of stabilization}

Let $S(T) \equiv \operatorname{Pr}\left\{\min \left(T_{1}\left(\theta_{1}\right), T_{2}\left(\theta_{2}\right)\right) \leq T\right\}$. Then, the expected time of stabilization is

$$
E(T)=\int_{0}^{\infty}(1-S(T)) d T=\int_{0}^{\infty} F_{1}\left(\phi_{1}(T)\right) F_{2}\left(\phi_{2}(T)\right) d T .
$$


We can approximate $E(T)$ using the trapezoidal rule as

$$
h\left(\frac{1}{2} F_{1}\left(\phi_{10}\right) F_{2}\left(\phi_{20}\right)+\frac{1}{2} F_{1}\left(\phi_{1 n}\right) F_{2}\left(\phi_{2 n}\right)+\sum_{k=1}^{n-1} F_{1}\left(\phi_{1 k}\right) F_{2}\left(\phi_{2 k}\right)\right) .
$$

Thus, $E(T)$ is approximated by $h$ times

$$
\begin{gathered}
\frac{1}{2}\left(\lambda_{1}\left(1-\phi_{10}\right)^{2}+\left(1-\lambda_{1}\right)\left(1-\phi_{10}\right)\right)\left(\lambda_{2}\left(1-\phi_{20}\right)^{2}+\left(1-\lambda_{2}\right)\left(1-\phi_{20}\right)\right) \\
+\frac{1}{2}\left(\lambda_{2}\left(1-\phi_{2 n}\right)^{2}+\left(1-\lambda_{2}\right)\left(1-\phi_{2 n}\right)\right) \\
+\sum_{k=1}^{n-1}\left(\lambda_{1}\left(1-\phi_{1 k}\right)^{2}+\left(1-\lambda_{1}\right)\left(1-\phi_{1 k}\right)\right) \\
\left(\lambda_{2}\left(1-\phi_{2 k}\right)^{2}+\left(1-\lambda_{2}\right)\left(1-\phi_{2 k}\right)\right) .
\end{gathered}
$$

Expected welfare

Group $i$ 's expected welfare is

$$
\begin{gathered}
E_{i}\left[V_{i}\left(t, T_{j}(\cdot) ; \theta_{i}\right)\right] \\
=\int_{\underline{\theta}}^{\bar{\theta}} V_{i}\left(t, T_{j}(\cdot) ; \theta_{i}\right) d F_{i}\left(\theta_{i}\right) \\
=\left\{\int_{\underline{\theta}}^{\bar{\theta}} \operatorname{Pr}\left\{T_{j}\left(\theta_{j}\right) \geq t\right\} \times\left[\int_{x=0}^{x=t} U_{i}^{D} e^{-r x} d x+\int_{x=t}^{x=\infty} U_{i}^{L} e^{-r x} d x\right]\right. \\
+\int_{\left\{\theta_{j}: T_{j}\left(\theta_{j}\right)<t\right\}}\left[\int_{x=0}^{x=T_{j}\left(\theta_{j}\right)} U_{i}^{D} e^{-r x} d x\right. \\
\left.\left.+\int_{x=T_{j}\left(\theta_{j}\right)}^{x=\infty} U_{i}^{W} e^{-r x} d x\right] d F_{j}\left(\theta_{j}\right)\right\} d F_{i}\left(\theta_{i}\right) \\
=\int_{0}^{\infty}\left[F_{j}\left(\phi_{j}(t)\right)\left(-\left(\frac{\tau}{2}+\phi_{i}(t)\right)\left(\left(1-e^{-r t}\right) / r\right)-\alpha \tau e^{-r t} / r\right)\right. \\
+\int_{0}^{t}\left(-\left(\frac{\tau}{2}+\phi_{i}(t)\right)\left(\left(1-e^{-r x}\right) / r\right)-(1-\alpha) \tau e^{-r x} / r\right) \\
\left.F_{j}^{\prime}\left(\phi_{j}(x)\right)\left|\phi_{j}^{\prime}(x)\right| d x\right] F_{i}^{\prime}\left(\phi_{i}(t)\right)\left|\phi_{i}^{\prime}(t)\right| d t .
\end{gathered}
$$

We can approximate the expected welfare as

$$
\begin{aligned}
& {\left[1-F_{i}\left(\phi_{i 0}\right)\right]((-\alpha) / r)+\left[1-F_{j}\left(\phi_{j 0}\right)\right]((-(1-\alpha)) / r)} \\
& +\sum_{k=1}^{n}\left[F_{j}\left(\phi_{j k}\right)\left(-\left(\frac{\tau}{2}+\phi_{i k}\right)\left(\left(1-e^{-r k h}\right) / r\right)-\alpha \tau e^{-r k h} / r\right)\right. \\
& +\sum_{l=1}^{k}\left(-\left(\frac{\tau}{2}+\phi_{i k}\right)\left(\left(1-e^{-r l h}\right) / r\right)-(1-\alpha) \tau e^{-r l h} / r\right) \\
& \left.F_{j}^{\prime}\left(\phi_{j l}\right)\left|\phi_{j l}-\phi_{j(l-1)}\right|\right] F_{i}^{\prime}\left(\phi_{i k}\right)\left|\phi_{i k}-\phi_{i(k-1)}\right| .
\end{aligned}
$$


Thus, group $i$ 's expected welfare is approximated by

$$
\begin{aligned}
& {\left[1-\left(\lambda_{i}\left(1-\phi_{i 0}\right)^{2}+\left(1-\lambda_{i}\right)\left(1-\phi_{i 0}\right)\right)\right]((-\alpha) / r)} \\
& +\left[1-\left(\lambda_{j}\left(1-\phi_{j 0}\right)^{2}+\left(1-\lambda_{j}\right)\left(1-\phi_{j 0}\right)\right)\right]((-(1-\alpha)) / r) \\
& +\sum_{k=1}^{n}\left[\left(\lambda_{j}\left(1-\phi_{j k}\right)^{2}+\left(1-\lambda_{j}\right)\left(1-\phi_{j k}\right)\right)\right. \\
& \left(-\left(\frac{\tau}{2}+\phi_{i k}\right)\left(\left(1-e^{-r k h}\right) / r\right)-\alpha \tau e^{-r k h} / r\right) \\
& +\sum_{l=1}^{k}\left(-\left(\frac{\tau}{2}+\phi_{i k}\right)\left(\left(1-e^{-r l h}\right) / r\right)-(1-\alpha) \tau e^{-r l h} / r\right) \\
& \left.\left.\left(2 \lambda_{j}\left(1-\phi_{j l}\right)+\left(1-\lambda_{j}\right)\right) \mid \phi_{j l}-\phi_{j(l-1)}\right)\right] \\
& \times\left(2 \lambda_{i}\left(1-\phi_{i k}\right)+\left(1-\lambda_{i}\right)\right) F_{i}^{\prime}\left(\phi_{i k}\right)\left|\phi_{i k}-\phi_{i(k-1)}\right| .
\end{aligned}
$$




\section{References}

[1] Acemoglu, Daron, Simon Johnson, James Robinson and Yunyong Thaicharoen (2003) Institutional Causes, Macroeconomic Symptoms: Volatility, Crises and Growth, Journal of Monetary Economics 50: 49123.

[2] Alesina, Alberto and Allan Drazen (1991) Why are Stabilizations Delayed?, American Economic Review 81: 1170-1188.

[3] Alesina, Alberto and Roberto Perotti (1995) The Political Economy of Budget Deficits, IMF Staff Papers (March), 1-31.

[4] Bliss, Christopher and Barry Nalebuff (1984) Dragon-Slaying and Ballroom Dancing: The Private Supply of a Public Good, Journal of Public Economics 23: 1-12.

[5] Bowen, Sally and Jane Holligan (2003) The Imperfect Spy: The Many Lives of Vladimiro Montesinos, Peisa, Lima, Peru.

[6] Bulow, Jeremy and Paul Klemperer (1999) The Generalized War of Attrition, American Economic Review 89: 175-189.

[7] Casella, Alessandra and Barry Eichengreen (1996) Can Foreign Aid Accelerate Stabilisation?, Economic Journal 106: 605-619.

[8] Cukierman, Alex and Mariano Tommasi (1998) When Does it Take a Nixon to Go to China?, American Economic Review 88: 180-197.

[9] Drazen, Allan (2000) Political Economy in Macroeconomics, Princeton University Press.

[10] Drazen, Allan and Vittorio Grilli (1993) The Benefits of Crises for Economic Reforms, American Economic Review 83: 598- 607.

[11] Erosa, Andrés and Gustavo Ventura (2000) On Inflation as a Regressive Consumption Tax, Journal of Monetary Economics 49: 761-795. 
[12] Fernandez, Raquel and Dani Rodrik (1991) Resistance to Reform: Status Quo Bias in the Presence of Uncertainty, American Economic Review 81: $1146-1155$.

[13] Fudenberg, Drew and Jean Tirole (1986) A Theory of Exit in Duopoly, Econometrica 54: 943-960.

[14] Guidotti, Pablo and Carlos Vegh (1999) Losing Credibility: The Stabilization Blues, International Economic Review 40: 23-51.

[15] Hirsch, Morris W. and Stephen Smale (1974) Differential Equations, Dynamical Systems, and Linear Algebra, Academic Press, San Diego.

[16] Hsieh, Chang-Tai (2000) Bargaining over Reform, European Economic Review 44: 1659-1676.

[17] Krishna, Vijay and John Morgan (1997) An Analysis of the War of Attrition and the All-Pay Auction, Journal of Economic Theory 72: 343-362.

[18] Labán, Raúl and Federico Sturzenegger (1994) Distributional Conflict, Financial Adaptation and Delayed Stabilizations, Economics \& 3 Politics 6: $257-278$.

[19] Maynard Smith, John (1974) The Theory of Games and the Evolution of Animal Conflicts, Journal of Theoretical Biology 47: 209-221.

[20] Nalebuff, Barry and John Riley (1985) Asymmetric Equilibria in the War of Attrition, Journal of Theoretical Biology 113: 517-527.

[21] Perraudin, William and Anne Sibert (2000) The Timing of Multilateral Lending, Economic Journal 110: 192-211.

[22] Persson, Torsten and Guido Tabellini (2000) Political Economics: Explaining Economic Policy, MIT Press.

[23] Riley, John (1980) Strong Evolutionary Equilibrium and the War of Attrition, Journal of Theoretical Biology 82: 383-400. 
[24] Robertson, John S. (1991) Numerical Methods, chapter 17 in George F. Simmons, Differential Equations with Applications $\&$ Historical Notes, McGraw-Hill.

[25] Rodrik, Dani (1996) Understanding Economic Policy Reform, Journal of Economic Literature 34: 9-41.

[26] Rodrik, Dani (1999) Where Did All the Growth Go? External Shocks, Social Conflicts, and Growth Collapses, Journal of Economic Growth 4: 358-412.

[27] Romer, Christina and David Romer (1998) Monetary Policy and the Well-Being of the Poor, Federal Reserve Bank of Kansas City - Economic Review 84: 21-49.

[28] Sargent, Thomas J. (1986) Rational Expectations and Inflation, Harper \& Row, Publishers, New York.

[29] Schelling, Thomas C. (1960) The Strategy of Conflict, Harvard University, Cambridge, Massachusetts.

[30] Seddon Wallack, Jessica (2003) Disagreement, Delay, and Deficits, mimeo, GSB Stanford University.

[31] Spolaore, Enrico (2003) Adjustments in Different Government Systems, forthcoming in Economics \& Politics.

[32] Sturzenegger, Federico (1997) Understanding the Welfare Implications of Monetary Substitution, Journal of Economic Dynamics and Control 21: 391-416. 